CASE REPORT

\title{
Successful surgical treatment of advanced erythema elevatum diutinum
}

\author{
Jeremy Ronald Rinard $\mathrm{MD}^{1}$, Raman Chaos Mahabir MD MS FRCSC ${ }^{1}$, \\ John F Greene Jr MD², Peter Grothaus MD FRCSC ${ }^{1}$
}

\begin{abstract}
JR Rinard, RC Mahabir, JF Greene Jr, P Grothaus. Successful surgical treatment of advanced erythema elevatum diutinum. Can J Plast Surg 2010;18(1):28-30.

Erythema elevatum diutinum is a rare, chronic cutaneous vasculitis that presents with plaques or nodules on the extensor surfaces of extremities. Although the exact pathogenesis is unknown, patients usually have an underlying systemic medical problem such as malignancy, autoimmune disease or HIV. Management of the cutaneous manifestations is aimed at controlling the underlying disease process, in addition to medical therapy directed at suppressing the lesions. The difficult case of a 60 -year-old man, who was not a candidate for medical therapy but has undergone successful surgical therapy of this rare disease for 10 years, is presented.
\end{abstract}

Key Words: Erythema elevatum diutinum, Rheumatoid nodule

$\mathrm{G}$ rythema elevatum diutinum (EED) is a rare, chronic cutaEneous vasculitis that manifests clinically as plaques or nodular lesions on the extensor surfaces of extremities (1). Diagnosis is based on clinical and histological findings. Early lesions appear as erythematous, macular lesions. If allowed to progress, the skin lesions become papular and eventually can become large and fibrotic in nature (late presentation) $(1,2)$.

Management is aimed at controlling the underlying systemic medical illness, in addition to medical therapy for control of the skin lesions. Chronic lesions are much less responsive to medical therapy.

The objective of the present case report was to describe a difficult case of EED, in which the patient presented with late

\section{Le traitement chirurgical réussi d'un erythema elevatum diutinum avancé}

L'erythema elevatum diutinum est une vasculite cutanée chronique rare qui se manifeste par des plaques ou des nodules sur les surfaces des muscles extenseurs des extrémités. Même si on n'en connaît pas la pathogenèse exacte, les patients ont généralement des troubles médicaux systémiques sous-jacents, tels que des tumeurs malignes, une maladie auto-immune ou le VIH. La prise en charge des manifestations cutanées vise à contrôler le processus pathologique sous-jacent, en plus d'une médicothérapie conçue pour supprimer les lésions. Est présenté le cas difficile d'un homme de 60 ans, qui n'était pas candidat à une médicothérapie, mais qui a subi une thérapie chirurgicale réussie de cette maladie rare dont il souffrait depuis dix ans.

lesions and was not a candidate for medical therapy. Despite the late presentation, delay in diagnosis and his inability to receive medical therapy for $E E D$, the patient has undergone successful surgical therapy for more than 10 years. In addition to describing the case, a brief review of EED will be provided.

\section{CASE PRESENTATION}

Twelve years previously, a 60-year-old African-American man with an allergy to sulpha drugs presented to his primary care physician. His chief complaint was multiple solitary nodules located mainly on the extensor surfaces of the elbow and metacarpophalangeal joints, which had been slowly growing over the previous five years (Figure 1). He was taking no medications,

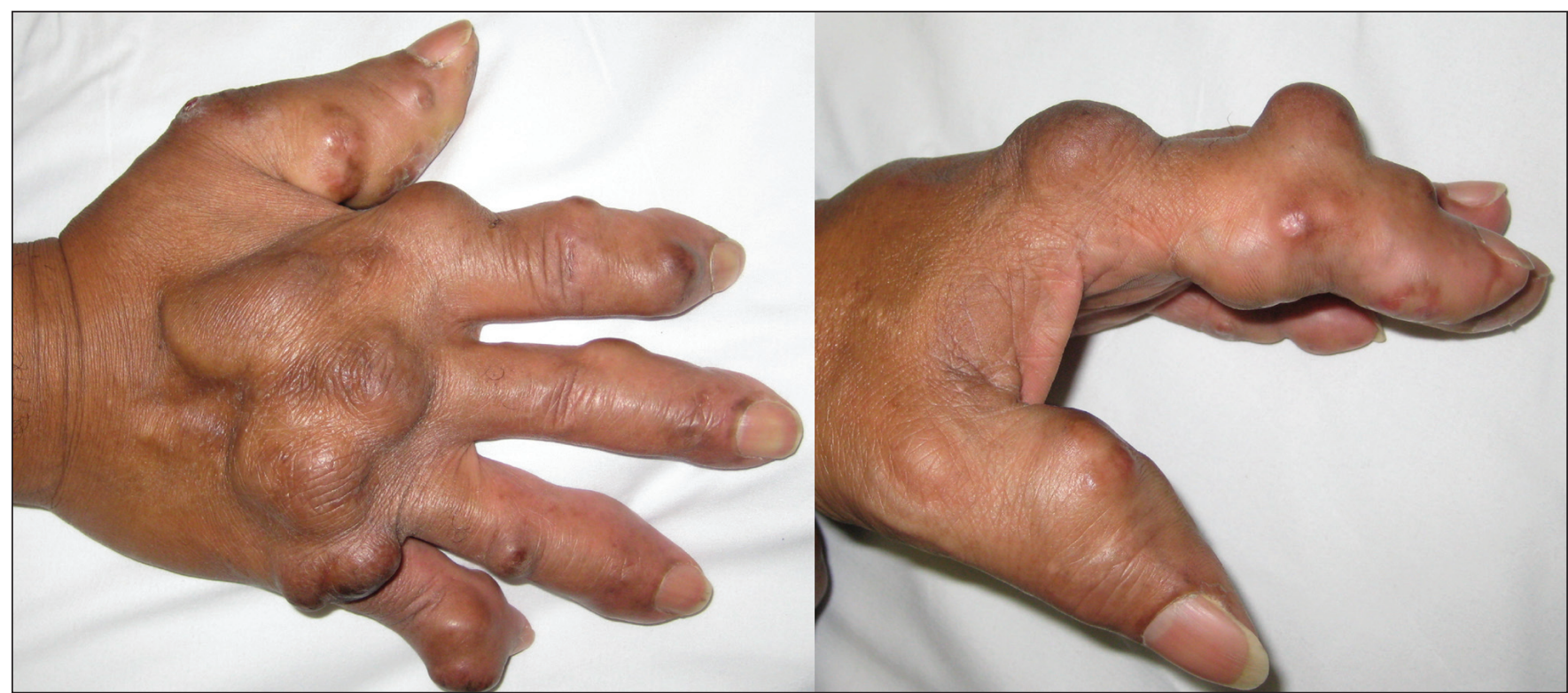

Figure 1) Anteroposterior (left) and lateral (right) views of hand demonstrating multiple erythema elevatum diutinum lesions

${ }^{1}$ Division of Plastic Surgery; ${ }^{2}$ Department of Pathology; Scott 83 White Healthcare, Texas AEM University, Temple, Texas, USA Correspondence: Dr Raman Chaos Mahabir, Division of Plastic Surgery, 2401 South 31st Street, Temple, Texas 76508, USA.

Telephone 254-724-2321, fax 254-724-0315, e-mail rmahabir@swmail.sw.org 


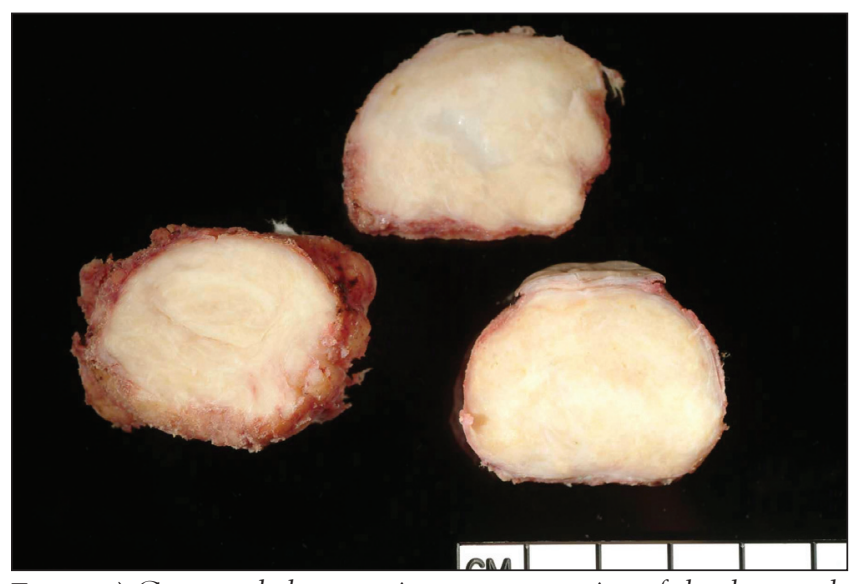

Figure 2) Gross pathology specimen: cross-section of the three nodules removed from the dorsum of the hand, as seen in Figure 1

and had no known medical problems with the exception of hypertension. The patient was referred to the dermatology department and diagnosed with nonspecific granulomatous dermatitis. Despite several intralesional steroid injections, there was minimal improvement in the nodules.

Because the symptoms related to size and ulceration became severe, he was referred to the plastic surgery department. At that time, the patient was noted to have numerous lesions over his elbows, metacarpophalangeal joints and knees, measuring between $2 \mathrm{~cm}$ and $6 \mathrm{~cm}$ in diameter and believed most likely to be rheumatoid nodules. The patient underwent excision of numerous nodules and healed without complication. Although a specific diagnosis was not made, the patient had significant relief of his symptoms after the excision of these nodules and, over the next four years, underwent three additional surgical excisions. Histopathology on all these specimens revealed features of sclerotic nodules with a whorled pattern of fibroblastic proliferation with variable foci of neutrophilic infiltration. During this interval, the differential diagnoses suggested by several pathologists and consultants included a neutrophilic dermatosis, EED, septic vasculitis, necrotizing granulomatous dermatitis with acute inflammation and connective tissue diseases. While not ruled out, the pathology did not support the diagnosis of rheumatoid nodules.

Unfortunately, the patient was lost to follow-up. After a sixyear lapse in treatment, he returned to Scott and White (Texas, USA) requesting further excision of the symptomatic nodules. He underwent another surgery, in which numerous nodules were excised without incident (Figure 2). On these specimens, the pathologist considered the histology most consistent with a diagnosis of late-stage EED. Subsequently, at a multidisciplinary conference, this diagnosis was confirmed and a trial of Dapsone (Jacobus Pharmaceutical Company Inc, USA) was proposed. However, because the patient was allergic to sulpha drugs and had a low glucose-6phosphate dehydrogenase (G6PD) level (1.30 units/g hemoglobin), he could not be treated with any first-line medical therapy, including Dapsone.

\section{DISCUSSION}

EED is a rare form of chronic cutaneous vasculitis that is usually associated with underlying disease processes such as hematological malignancies, connective tissue disorders, chronic infections, inflammatory bowel disease, HIV and streptococcal

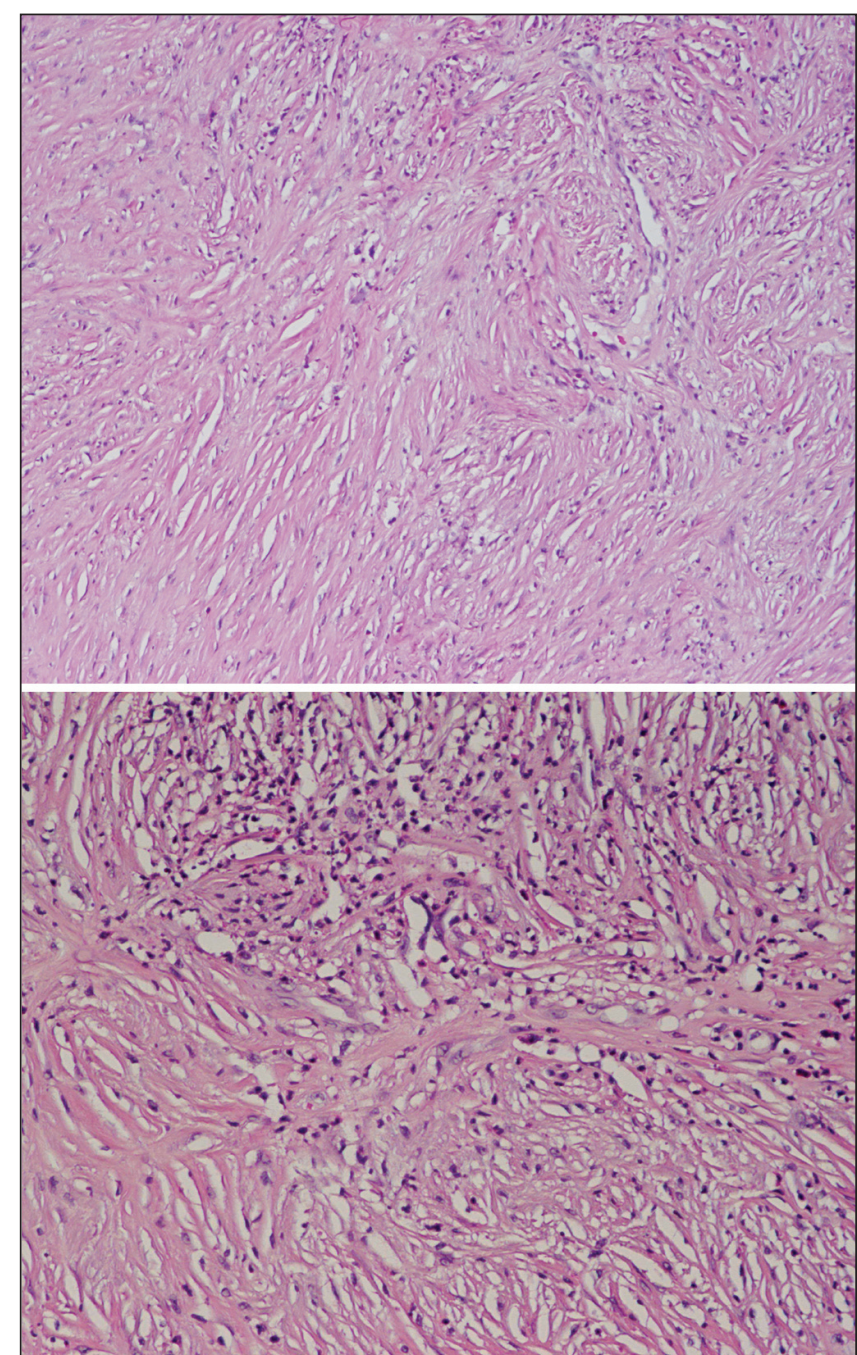

Figure 3) Whorled fibromatous histological pattern (hematoxylin and eosin stain; original magnification $\times 100$ ) (top) and fibromatous pattern and cellular area with perivascular neutrophils (hematoxylin and eosin stain; original magnification $\times 200$ ) (bottom)

infections $(3,4)$. The present case is unusual in the fact that the patient had no detectable underlying illness. Although the diagnosis of EED is often delayed, the case is also unique in the fact that it was treated successfully with surgery for over 10 years.

Patients with EED usually present with plaques or nodular lesions located at the extensor surfaces of joints (often elbow, knees and metacarpophalangeal) and, in general, present between 40 and 60 years of age (5). These lesions are often symmetrically located and start as plaques that further develop into nodular lesions. These lesions can be quite problematic if untreated, resulting in ulceration, pain and open wounds.

The histological features of early lesions are mainly neutrophilic infiltrates around vessels with fibrin deposition in and around the vessel walls, but with little red blood cell extravasation or other features of vasculitis (5). Late histological findings demonstrate a proliferation of fibroblasts that may, as in the present case, develop into large fibrotic nodules. At this stage, the histological appearance is that of a patterned fibroma often resembling a sclerosing fibroma or fibrous histiocytoma, or may even be confused with dermatofibrosarcoma protuberans (Figure 3). 
The distinguishing feature of EED at this stage is the continuing presence of perivascular neutrophils, sometimes in large numbers (Figure 3).

A histological and clinical diagnosis consistent with EED warrants further investigation for systemic disease processes (6). On laboratory workup, the only abnormalities noted were a mild, chronic anemia, a slightly elevated erythrocyte sedimentation rate and a G6PD deficiency.

Treatment of EED skin lesions involves controlling the systemic disease process and prescribing medications that aim to stop progression and initiate regression of the lesions (5). Dapsone is the first-line medication and usually works well to control the lesions (5). Other pharmacological treatments are available and include sulphonamides, antimalarials, intralesional corticosteroids and oral corticosteroids. Unfortunately for our patient, his underlying G6PD deficiency was a contraindication to treatment with sulphonamides and antimalarials. Intralesional steroids had been tried with minimal results.
Due to his advanced pathology and the fact that he was unable to undergo medical therapy, the final disposition from the most recent multidisciplinary conference was for continued surgical management as indicated for symptomatic relief.

\section{REFERENCES}

1. Crowson AN, Mihm MC Jr, Magro CM. Cutaneous vasculitis: A review. J Cutan Pathol 2003;30:161-73.

2. LeBoit P, Yen TS, Wintroub B. The evolution of lesions in erythema elevatum diutinum. Am J Dermatopathol 1986;8:392-402.

3. Golmia A, Grinblat B, Finger E, Klieman C, Assir F, Scheinberg M. The development of erythema elevatum diutinum in a patient with juvenile idiopathic arthritis under treatment with abatacept. Clin Rheumatol 2008;27:105-6.

4. Nakajima H, Ikeda M, Yamamoto Y, Kodama H. Erythema elevatum diutinum complicated by rheumatoid arthritis. J Dermatol 1999;26:452-6.

5. Gibson LE, el-Azhary RA. Erythema elevatum diutinum. Clin Dermatol 2000;18:295-9.

6. Ly H, Black MM. Atypical presentation of erythema elevatum diutinum. Australas J Dermatol 2005;46:44-6. 